\section{Edyrcasace

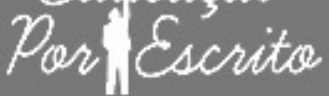

ARTIGO

\section{Editor}

Alexandre Anselmo Guilherme PUCRS, RS, Brasil

\section{Editor Assistente}

Cibele Cheron

PUCRS, RS, Brasi

\section{Editores Associados}

Bruno Antonio Picoli

Universidade Federal da Fronteira Sul, Chapecó, SC, Brasil

Pricila Kohls dos Santos Universidade Católica de Brasília, Brasília, DF, Brasil

Renato de Oliveira Brito

Universidade Católica de Brasilia, Brasilia, DF, Brasil

Elisa Ustarroz

PUCRS, Porto Alegre, RS, Brasil

\section{ISSN 2179-8435}

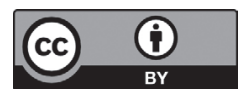

Este artigo está licenciado sob forma de uma licença Creative Commons Atribuiçăo 4.0 Internacional, que permite uso irrestrito, distribuicăo e reprodução em qualquer meio, desda
seja corretamente citada

\title{
As novas tecnologias e o ensino de História como temática de pesquisas nas universidades brasileiras
}

\section{The new technologies and the teaching of History as the theme of research}

in Brazilian universities

\section{Paulo Augusto Tamanini 1 Maria do Socorro Souza 1}

${ }^{1}$ Universidade Federal Rural do Semi-Árido, Mossoró, RN, Brasil.

\section{RESUMO}

A presença das novas tecnologias na sociedade e na educação tem encetado uma era de incertezas, imprevisibilidades e mudanças. No ensino de História, não é diferente, o que demanda um repensar sobre a metodologia usada nas aulas, bem como o papel do professor e do aluno nesse contexto. Este estudo constitui, portanto, um estado da arte, pesquisa cujo fim é realizar um mapeamento das produções acadêmicas que abordam o uso das novas tecnologias no ensino de História, revelando o que está sendo produzido nos últimos anos sobre esse tema, buscando identificar tanto as tendências investigativas a ele concernentes como as principais contribuições e lacunas nesse campo teórico. Para isso, realizou-se uma busca no Catálogo de Teses e Dissertações da Capes e outra no Portal de Periódicos da Capes, seguidas da descrição analítica dos dados ali encontrados. Os resultados visibilizam lacunas informacionais nos títulos e nos resumos; a preocupação em buscar modos de inovar o ensino de História, via inserção das tecnologias na prática pedagógica; emergência do tema pesquisado como tendência investigativa, com a predominância da internet e os seus recursos; e, apesar disso, uma produção e uma divulgação incipientes nessa área temática, havendo necessidade de estimular a pesquisa e a produção nesse campo.

Palavras-chave: Novas tecnologias. Ensino de História. Estado da Arte. Catálogo de Teses e Dissertações da Capes. Portal de Periódicos da Capes.

\section{ABSTRACT}

The presence of new technologies in society and in education has begun an era of uncertainties, unpredictabilities and changes. In the teaching of History, it is no different, which demands that one rethinks the used methodology in classroom, as well as the role of the teacher and the student in this context. This study is, therefore, a stateof-the-art research whose aim is mapping the academic productions that approach the use of new technologies in the teaching of History, revealing what has been produced in recent years on this subject, to identify both 
the relevant research trends and the main contributions and gaps in this field. For this, a search was made in the Theses and Dissertations Catalog of CAPES and another in the Periodicals Portal of CAPES, followed by the analytical description of the data found there. The results show information gaps in the titles and abstracts; the concern to find ways innovating the teaching of History via the insertion of technologies in the pedagogical practice; the emergence of the researched subject as an investigative tendency, with predominance of the internet and its resources; and, nonetheless, an incipient production and dissemination in this thematic area, thus making necessary to stimulate research and production in this field.

Keywords: New Technologies. Teaching of History. State of the art. Theses and Dissertations Catalog of Capes. Periodicals Portal of Capes.

\section{Introdução}

s pesquisas denominadas de estado da arte, amplamente reconhecidas e utilizadas no âmbito acadêmico, possuem natureza bibliográfica e vêm possibilitando mapear as produções universitárias nos mais variados campos do conhecimento científico, tanto no que concerne aos temas que vêm sendo privilegiados em um dado período e região, quanto às metodologias e teorias subjacentes utilizadas na pesquisa desses temas (FERREIRA, 2002). A relevância desse tipo de estudo encontra-se no fato de ser possível, dessa forma, identificar que dimensões de um dado tema se sobressaiu ou foi esquecido, possibilitando, assim, apontar que aspectos podem ser alvo de futuras investigações (ANDRÉ, 2009).

O tema da presente pesquisa, novas tecnologias e ensino de História, vem atender a um requisito avaliativo da disciplina "Ensino de História: fontes, metodologias e abordagens", ofertada no âmbito do Mestrado em Ensino, da Universidade do Estado do Rio Grande do Norte (UERN), Universidade Federal Rural do Semiárido (UFERSA) e do Instituto Federal de Educação, Ciência e Tecnologia do Rio Grande do Norte (IFRN).

As denominadas novas tecnologias, em especial a internet, abriram possibilidades de informação, comunicação e interação sem precedentes na história da humanidade. Redes sociais virtuais, hipertexto, ubiquidade, conectividade, produção e compartilhamento de conteúdo em rede, enfim, são tantas inovações e possibilidades que o indivíduo do mundo contemporâneo se sente impossibilitado de acompanhá-las. Arruda (2013) assevera que a disseminação da internet ampliou o acesso à produção da cultura, mas que é necessário analisar os contextos onde essas informações e conhecimentos são produzidos. Ao abordar o universo de conteúdo e informação que é produzido pela rede, o autor aduz ainda que há uma primazia do acessar, armazenar o material produzido, em detrimento do conhecê-lo. 
A disciplina de História, por ser crucial na construção de uma sociedade democrática e cidadã, que conecta o presente ao passado e direciona o olhar para um futuro a ser construído, deve se apropriar das novas Tecnologias da Informação e Comunicação e dos novos saberes construídos com a sua mediação, analisando como essas ferramentas podem ser usadas para dinamizar o ensino dessa disciplina e ampliar o repertório cultural dos alunos, minimizando a desigualdade social e promovendo a cidadania na escola. Cabe ao professor de História, por conseguinte, inserir, de modo crítico e reflexivo, esses recursos nas suas aulas

Em razão disso, averiguar o estado da arte no que se refere às novas tecnologias e ensino de História não é algo improfícuo, especialmente se entendermos que, além de as tecnologias digitais poderem contribuir significativamente para dinamizar o ensino dessa disciplina, o resultado desse levantamento pode possibilitar uma visão do que já foi estudado e dos silenciamentos nesse campo, o que levará a possíveis percursos de pesquisa.

Nesse viés, este trabalho, por ser uma pesquisa do tipo estado da arte, tem como fim sistematizar, por meio do levantamento, descrição e análise do conteúdo dos títulos, palavras-chave e resumos das obras encontradas, as produções acerca das novas tecnologias e ensino de História nos Programas de Pós-Graduação de instituições brasileiras, particularmente aquelas disponibilizadas no Catálogo de Teses e Dissertações da Coordenação de Aperfeiçoamento de Pessoal de Nível Superior (Capes), bem como os artigos publicados no Portal de Periódicos dessa mesma instituição. Espera-se, dessa forma, identificar tanto as tendências investigativas como as contribuições e lacunas na área. Com base no exposto, a questão que irá nortear essa pesquisa é: o que tem sido produzido, em nível de pós-graduação stricto sensu e de publicação em revistas acadêmicas, indexadas no Portal de Periódicos da Capes, sobre as novas tecnologias e o ensino de História?

Quanto à metodologia, será usada uma abordagem quanti-qualitativa, por permitir abarcar, de modo mais completo, a realidade pesquisada (MINAYO; SANCHES, 1993). O estudo está dividido em duas partes: a primeira apresenta a contextualização do tema e a segunda, a descrição e a análise dos dados encontrados.

\section{As novas tecnologias e o ensino de História}

Mediante a popularização do computador e da internet no Brasil, na década de 1990, e as modificações em ritmo exponencial em todos os âmbitos da sociedade por eles provocados, começa-se a perceber atualmente a necessidade de rever o ensino de História e a sua metodologia, a partir da inserção das tecnologias na sala de aula. Bitencourt afirma que é impossível evitar essas mudanças culturais causadas pelos computadores e meios audiovisuais, porque "geram sujeitos com novas habilidades e diferentes capacidades de entender o mundo" (2011, p. 108). 
Para Seffner (2013, p. 32), a aula de História deve "possibilitar que o aluno se interrogue sobre sua própria historicidade" - incluindo-se, aí, família, sociedade, país, estado etc. -, que reflita sobre o seu contexto, o que o levará a um pensar crítico e emancipatório, tornando-o, desse modo, consciente do seu papel na sociedade enquanto cidadão. Dessa forma, o ensino adquirirá significado para o aluno.

Nesse sentido, para que o ensino de História passe a ser significativo para o aluno e caminhe de mãos dadas com o contexto onde esse está inserido, é preciso que o professor insira nesse processo as novas Tecnologias da Informação e Comunicação. Só inserir as tecnologias, contudo, não resolve. É preciso, de igual modo, mudar a forma de ensinar. Bittencourt (2008), ao defender a necessidade de o ensino de História se renovar, abordando as características do método tradicional, centrado no professor e na concepção de ensino como transmissão e repetição de conhecimento, sem levar em conta o repertório cultural que o aluno possui, deixa claro que é possível o professor utilizar o método tradicional e, ainda, assim, empregar as tecnologias mais sofisticadas,

[...] desde que a finalidade principal do uso desse suporte tecnológico seja apenas facilitar a melhor transmissão do conhecimento, sem estabelecer as necessárias relações entre o conhecimento do aluno e o escolar. Renova-se o instrumento, mas fica mantido o método tradicional, ao consolidar a noção de que o saber histórico (ou o de qualquer outra disciplina) significa apenas a absorção do que foi transmitido (BITTENCOURT, 2008, p. 230).

Cabe ao professor, portanto, adotar estratégias e recursos que conduzam o aluno a se situar no seu tempo de forma crítica e a ser autor de seu próprio processo de aprendizagem. As tecnologias, nesse sentido, podem contribuir inegavelmente. O ciberespaço, descrito por Lévy (1999) como o espaço da troca de saberes, potencializador da inteligência coletiva, de novas práticas democráticas; o caráter lúdico das mídias digitais, em especial os jogos digitais, influenciando as narrativas históricas, modificando, assim, as formas de lidar com o conhecimento histórico (ARRUDA, 2014); as redes sociais, conectando culturas, ultrapassando fronteiras; a inovação da linguagem, entre outros, são alguns exemplos do que as tecnologias, em especial, a internet e o ciberespaço, podem proporcionar ao ensino de História. Ademais, se o contexto do aluno, a sua cultura e a historicidade devem ser levadas em conta na sala de aula de História, as tecnologias, parte do seu universo cotidiano, não podem ser ignoradas. Em uma realidade em que o real e o virtual se mesclam, amalgamando-se, é preciso romper com o ensino unidirecional, anacrônico, memorístico, transmissivista e desinteressante.

O professor de História não pode ficar alheio a essa nova dinâmica que as tecnologias fizeram despontar. Ele precisa entendê-la para poder atuar nessa sociedade em que a mudança é a única constante; sociedade que, por 
estar em incessante mutação, a tudo modifica. Trabalhar os conteúdos históricos em harmonia com essa sociedade conectada e com o perfil de aluno de hoje demanda, pois, do professor desenvolver, por meio da internet e dos diversos recursos tecnológicos disponíveis na sociedade e na escola, estratégias mais ativas, que favoreçam, em linguagens e recursos familiares ao aluno (webquest, podcast, jornais online, museus virtuais, mapas interativos, jogos educativos, simulações, animações, $b \log s$, fóruns etc.), a desconstrução e reconstrução crítica dos conhecimentos e acontecimentos históricos, disseminados nos livros oficiais, cotejando-os com pontos de vista diferenciados.

Para que esse objetivo seja atendido, o aluno, com o seu contexto cultural e social, precisa ser o centro e o autor do processo. Caso contrário, as tecnologias servirão somente para reforçar um ensino fragmentado, dissociado da vida do aluno e, conseguintemente, alijado de significado para ele.

\section{Análise descritiva dos dados}

O objetivo do trabalho consistiu em realizar o levantamento dos estudos acerca das novas tecnologias e ensino de História, tendo como corpus de análise as dissertações de mestrado e teses de doutorado disponibilizadas no Catálogo de Teses e Dissertações da Capes ${ }^{1}$, por abrangerem a produção acadêmica de Programas de Pós-Graduação de todos o País, e artigos de periódicos, disponibilizados no Portal de Periódicos da Capes, para expandir o campo da pesquisa.

A busca no Catálogo de Teses e Dissertações da Capes retornou 12.754 obras. Já o Portal de Periódicos da Capes retornou 21 artigos. Romanowski e Ens (2006, p. 39) definem estado da arte como aquele que abrange "toda uma área do conhecimento, nos diferentes aspectos que geraram produções", ou seja, que envolve vários setores de publicações, e não apenas um setor das publicações do tema estudado. No presente trabalho, a busca foi realizada em dois portais: Portal de Teses e Dissertações e Portal de Periódicos, ambos da Capes, configurando-se, por essa razão, em um estado da arte.

Para Romanowski e Ens (2006), a pesquisa tipificada como estado da arte deve ser compreendida como um estudo descritivo e, ao mesmo tempo, analítico. Para elas, no desenvolvimento de tal pesquisa, é preciso adotar alguns procedimentos, tais como:(a) definir descritores, para nortear as buscas; (b) localizar bancos de pesquisas, teses e dissertações, catálogos e acervos de bibliotecas etc.; (c) estabelecer critérios de seleção do material que constitui o corpus do estudo; (d) fazer o levantamento de teses e dissertações catalogadas; e (e) ler as publicações, elaborando

\footnotetext{
1 A Coordenação de Aperfeiçoamento de Pessoal de Nível Superior (Capes) é uma fundação do Ministério da Educação (MEC) que desempenha um relevante papel fundamental na expansão e consolidação da pós-graduação stricto sensu (mestrado e doutorado) em todo o País. Uma de suas atividades mais relevantes é possibilitar o acesso e a divulgação da produção científica. Por meio do seu endereço eletrônico é possível o acesso ao Catálogo de Teses e Dissertações. Disponível em: http://catalogodeteses.capes.gov.br/catalogo-teses. Acesso em: 4 nov. 2019.
} 
síntese preliminar, que contenha tema, objetivos, problemáticas, metodologias, conclusões e relação pesquisador e área etc. Tentando seguir alguns dos passos propostos pelas autoras, adotou-se, no presente estado da arte, os procedimentos que se seguem.

\subsection{Análise descritiva dos dados coletados nas teses e dissertações da Capes}

No dia 5 de setembro de 2018, após a definição dos descritores, Ensino de História e Novas Tecnologias, foi feita a busca no Catálogo de Teses e Dissertações da Capes, acessando o site da fundação², clicando em Plataformas e, em seguida, em Catálogo de Teses. Ambos os descritores foram utilizados entre aspas e separados por um ponto e vírgula (;), pois as aspas permitem obter um resultado mais preciso, já que a busca é feita considerando os termos sequenciados, tais quais se apresentam, sem separá-los. Por outro lado, o sinal de pontuação ponto e vírgula apresenta resultados que interligam as duas expressões. Feita a busca, foram encontrados 12.754 resultados.

Para enxugar os resultados, foram utilizados os seguintes critérios de inclusão/exclusão: tendo em vista a celeridade com que as tecnologias se modificam e, com elas, o conhecimento, foi definido um critério de delimitação temporal para a busca: de 2013 a 2018, o que reduziu o total de obras para 5.302. Considerando o pertencimento da disciplina História à área das Ciências Humanas, no filtro Grande área: conhecimento, foram selecionadas somente aquelas intituladas Ciências Humanas. O número de estudos retrocedeu para 1.456. Usando o critério de exclusão de divisão disciplinar, em Área Conhecimento, foram escolhidas somente as disciplinas que se relacionavam com História e Ensino, o que resultou em 12 obras. Ao final do processo de filtragem, só restaram dissertações. Seguiu-se, então, para o acesso na Plataforma Sucupira das páginas das 12 obras para a leitura dos títulos, palavras-chave e resumos.

Quanto à metodologia utilizada para selecionar, dentre os doze estudos encontrados, aqueles que tinham pertinência com os descritores pesquisados, lançou-se mão, inicialmente, da leitura dos títulos, pois eles, "normalmente anunciam a informação principal do trabalho ou indicam elementos que caracterizam o seu conteúdo" (FERREIRA, 2002, p. 261). Percebeu-se, contudo, que alguns dos títulos não continham as informações buscadas, fazendo-se necessário ler os resumos e as palavras-chave. A partir dessa leitura, foram eliminados os estudos que não tinham afinidade com o objeto da pesquisa. Quando, por falta de clareza do resumo, havia alguma dúvida com relação ao tema, objetivos, metodologia e base teórica da pesquisa, era feito o download do texto completo e lida a introdução e, algumas vezes, até a conclusão da obra analisada.

No total, das doze obras encontradas no Catálogo de Teses e Dissertações da Capes, foram descartadas quatro, por não apresentarem conexão com os dois descritores utilizados na busca, restando, ao final desse processo de

2 Disponível em: www.capes.gov.br. Acesso em: 5 set. 2018. 
filtragem e seleção, apenas oito dissertações. Duas obras não estavam disponíveis para download no Portal. Nesse caso, foi feita a pesquisa das referidas obras na ferramenta de busca do Google, que as encontrou, uma no site Educapes $^{3}$ e outra, no repositório da universidade onde foi defendida.

Para descrever e analisar as oito obras encontradas nos Portais da CAPES, os dados foram organizados a partir dos seguintes elementos: título, autor, orientador, ano da defesa, instituição e região, tipo de mestrado (acadêmico ou profissional), objetivos, metodologia e base teórica. No Quadro 1, podemos visualizar a descrição de alguns desses elementos:

\section{Quadro 1. Descrição das obras coletadas}

\begin{tabular}{|c|l|l|l|l|l|}
\hline & Título & Autor & Orientador & Ano & Instituição \\
\hline 01 & $\begin{array}{l}\text { Fernão Lopes (1380-1460) nas escolas: } \\
\text { contribuições para a introdução da obra } \\
\text { cronística portuguesa nas escolas por meio } \\
\text { das novas tecnologias de informação }\end{array}$ & Jose Édson dos Santos & Adailson José Rui & 2016 & $\begin{array}{l}\text { Universidade Federal de } \\
\text { Alfenas - MG }\end{array}$ \\
\hline 02 & $\begin{array}{l}\text { Da fé se valem os belicosos: uma } \\
\text { perspectiva educacional sobre a cavalaria } \\
\text { nas cantigas de Santa Maria }\end{array}$ & $\begin{array}{l}\text { Carolina Minardi de } \\
\text { Carvalho }\end{array}$ & $\begin{array}{l}\text { André Luís Pereira } \\
\text { Miatello }\end{array}$ & 2016 & $\begin{array}{l}\text { Universidade Federal de } \\
\text { Alfenas - MG }\end{array}$ \\
\hline 03 & $\begin{array}{l}\text { Jogando com a crítica histórica: as novas } \\
\text { tecnologias e o desenvolvimento de Os } \\
\text { revoltosos! }\end{array}$ & $\begin{array}{l}\text { Lucas Roberto Soares } \\
\text { Lopes }\end{array}$ & Sílvia Liebel & 2016 & UDESC \\
\hline 04 & $\begin{array}{l}\text { Espaços públicos, saberes públicos: um } \\
\text { podcast como espaço de ensino de história }\end{array}$ & Daniel Carvalho Pereira & $\begin{array}{l}\text { Sônia Maria de Almeida } \\
\text { Ignatiuk Wanderley }\end{array}$ & 2016 & UERJ \\
\hline 05 & $\begin{array}{l}\text { Urraca e a governança feminina: uma } \\
\text { análise das representações sociais na } \\
\text { Península Ibérica medieval }\end{array}$ & Janaína dos Reis Alves & Cláudia Regina Bovo & 2017 & $\begin{array}{l}\text { Universidade Federal de } \\
\text { Alfenas - MG }\end{array}$ \\
\hline 06 & $\begin{array}{l}\text { A utilização do mecanismo de busca } \\
\text { do Google na pesquisa e no ensino de } \\
\text { História: explorando possibilidades }\end{array}$ & $\begin{array}{l}\text { Marcelo Marcos de } \\
\text { Araújo }\end{array}$ & Braz Batista Vas & 2017 & UFT/TO \\
\hline 07 & $\begin{array}{l}\text { As abordagens da História Ibérica Medieval } \\
\text { nos livros didáticos da Educação Básica }\end{array}$ & Maria Aparecida Avelino & Fabiana de Oliveira & 2017 & $\begin{array}{l}\text { Universidade Federal de } \\
\text { Alfenas - MG }\end{array}$ \\
\hline 08 & $\begin{array}{l}\text { RPG e ensino de História: uma articulação } \\
\text { potente para a produção da narrativa } \\
\text { histórica escolar }\end{array}$ & $\begin{array}{l}\text { Carlos Eduardo de } \\
\text { Souza Costa }\end{array}$ & Carmen Teresa Gabriel & 2017 & UFRJ \\
\hline
\end{tabular}

Fonte: Quadro desenvolvido pelos autores (set. 2018).

3 Disponível em: https://educapes.capes.gov.br. Acesso em: 4 dez. 2019. 
Nos dados do Quadro 1, é possível observar que os resultados obtidos junto ao Portal de Teses e Dissertações da Capes referem-se apenas aos anos de 2016 e 2017, embora tenha sido aplicado o recorte temporal de 2013 a 2018. Isso comprova que a produção acadêmica relacionada ao tema novas tecnologias e ensino de História tem sido bastante incipiente, haja vista as tecnologias, notadamente a internet, terem se popularizado no Brasil desde a década de 1990. Tal fato pode ser originado do medo de inovar, de superar o tradicional, conforme Fonseca (2012), em semelhante estudo realizado em 2011, já destacava:

Apesar dos consensos construídos ao longo das últimas décadas na prática escolar e mesmo na acadêmica, persistem dificuldades, resistências às inovações, à superação dos tradicionais modos de ensinar e aprender. Um indicador significativo é a produção científico-acadêmica que tem como objeto de investigação o ensino e a aprendizagem em História e as TDIC. Um levantamento realizado por nós, em 2011, no Banco de Dissertações e Teses da Capes, alimentado por informações dos programas de pós-graduação no Brasil, revelou ser bastante incipiente a pesquisa nessa área. Em mais de uma década, foram localizadas seis dissertações de mestrado e duas teses de doutorado sobre essa matéria (FONSECA, 2012, p. 365-366).

Por outro lado, esse resultado, apesar de insatisfatório, também demonstra que o tema está entre os emergentes nos últimos três anos. Nesse sentido, a pesquisa demonstra que esse interesse se centraliza mais em nível de mestrado, tendo em vista que todos os trabalhos se enquadram na categoria dissertação. A explicação pode advir do fato de que, segundo a Capes há, no Brasil, 2.122 programas de pós-graduação em âmbito de mestrado, incluindo mestrado profissional, contrapondo-se a 81 programas de doutorado 4 .

Quanto à categoria Região, os dados demonstram que a região Sudeste predominou no estudo do tema, destacando-se com $75 \%$ da produção. A região Sul e a região Centro-Oeste ficaram, cada uma, com 12,5\% da produção. Uma explicação para o fato de a região Sudeste predominar pode estar vinculada à quantidade de programas de pós-graduação existente na região Sudeste, cuja taxa é a mais alta do País 5 .Com relação à categoria Instituição, das oito obras encontradas, seis foram produzidas em instituições federais, enquanto duas, em instituições estaduais. Vale salientar que, de acordo com dados do Índice Geral de Cursos (IGC) - INEP/MEC ${ }^{6}$, de 2016, no Brasil, das 230 instituições superiores existentes, 100 (cem) são federais e 35, estaduais, o que explica os índices do atual estudo.

4 Dados retirados da Plataforma Sucupira-CAPES/MEC: Cursos Avaliados e Reconhecidos. Disponível em: https://sucupira.capes.gov.br/ sucupira/public/consultas/coleta/programa/quantitativos/quantitativoRegiao.jsf. Acesso em: 14 set. 2018.

5 Dados obtidos na Plataforma Sucupira - CAPES/MEC: Cursos Avaliados e Reconhecidos. Disponível em: https://sucupira.capes.gov.br/ sucupira/public/consultas/coleta/programa/quantitativos/quantitativoRegiao.jsf. Acesso em: 14 set. 2018.

6 O Índice Geral de Cursos (IGC) é um indicador de qualidade que avalia, anualmente, as Instituições de Educação Superior. 
No que concerne ao tipo de pesquisa, a leitura dos resumos das oito obras evidenciou uma grande lacuna, já que $50 \%$ das dissertações analisadas não informaram o tipo de pesquisa desenvolvida. Das $50 \%$ restantes, entre os tipos mencionados, foram citados: pesquisa bibliográfica, estudo de caso e documental, tendo se destacado a pesquisa documental, que foi citada em 3 dos 4 trabalhos restantes. Houve uma obra que dividiu em duas fases a investigação, usando, assim, dois tipos de pesquisa: a documental e o estudo de caso. Com relação às técnicas de coleta de dados, aqui também se identificou uma enorme lacuna nos resumos, pois apenas um estudo explicitou que técnica utilizou; no caso, a entrevista.

Outra lacuna percebida em alguns resumos foi a ausência de informação acerca da teoria e/ou teóricos que embasaram os estudos. Das 8 pesquisas, 5 não informaram que teoria e/ou teóricos serviram de base para o estudo desenvolvido, tendo sido necessário buscar essa informação na Introdução e/ou Conclusão do trabalho.

Nesse quesito, foram citados algumas teóricos e vertentes teóricas, que podem ser divididos em dois grupos: (a) um vinculado à História e seu ensino: José Mattoso, Antonio Borges Coelho e Adam Schaff - crônica e narrativa histórica; Circe Bittencourt, Selva Guimarães Fonseca - ensino de História; Serge Moscovici - Teoria da Representação Social; Roger Chartier - noções de Práticas e Representações, História do tempo presente; Jörn Rüsen - consciência histórica, Didática da História; Anita Luchesi - História Digital e História Pública; Paul Ricoeur e Rüsen - estrutura narrativa do conhecimento histórico; Pierre Bayle - Crítica Histórica; Jacques Le Goff, Jean Claude Schmitt - História Ibérica Medieval; Jaime Pinsky, Carla Bassanezi Pinsky - fontes históricas; e (b) outro ligado às tecnologias e à educação: Michel Foucault e Pierre Bourdieu - educação e sentidos atribuídos ao ato educativo; Vani Moreira Kenski, José Manuel Moran - relação educação e tecnologias; Pierre Lévy - Ciberespaço e cibercultura, inteligência coletiva; André Lemos - tecnologias, cibercultura, ciberdemocracia; Henry Jenkins - conhecimento convergente, mídias, cultura participativa e inteligência coletiva.

A base teórica das pesquisas revelou que, em regra, os pesquisadores buscam fundamentação distinta tanto para a parte relativa à História e o seu ensino como para aquela que trata das tecnologias, o que evidencia uma certa dificuldade em encontrar uma teoria que relacione os dois temas: ensino de História e tecnologias. A pesquisa demonstrou, também, que, apesar de os trabalhos citarem vários autores brasileiros, prevalece a escolha por autores estrangeiros, como Jacques Le Goff, Roger Chartier, Jörn Rüsen, Paul Ricoeur, Pierre Bourdieu, Pierre Lévy, Serge Moscovici, tanto para os temas vinculados às tecnologias quanto para aqueles referentes à História. A questão que surge é: será que esses estudiosos, ao pesquisar/aplicar as teorias estrangeiras, percebem que representam um contexto social e educacional diferente do brasileiro?

Um fato que chamou bastante a atenção foi o de que $100 \%$ das dissertações analisadas pertencem a programas de Mestrado Profissional. A razão está, possivelmente, na oferta, em várias universidades brasileiras, do Mestrado 
Profissional em ensino de História (PROFHISTÓRIA), reconhecido pela Capes e ofertado em formato semipresencial, com vistas a capacitar os professores de História da rede pública de ensino.

Ao analisar os títulos das oito dissertações, com vistas a obter-se uma visão mais global do que está sendo investigado relativo ao tema do estado da arte, as obras foram divididas por categorias temáticas, em conformidade com o assunto abordado: a) Recursos educativos virtuais; b) Ferramentas virtuais e; c) Jogos digitais, conforme ilustra o Quadro 2.

Quadro 2. categorias de análise das obras

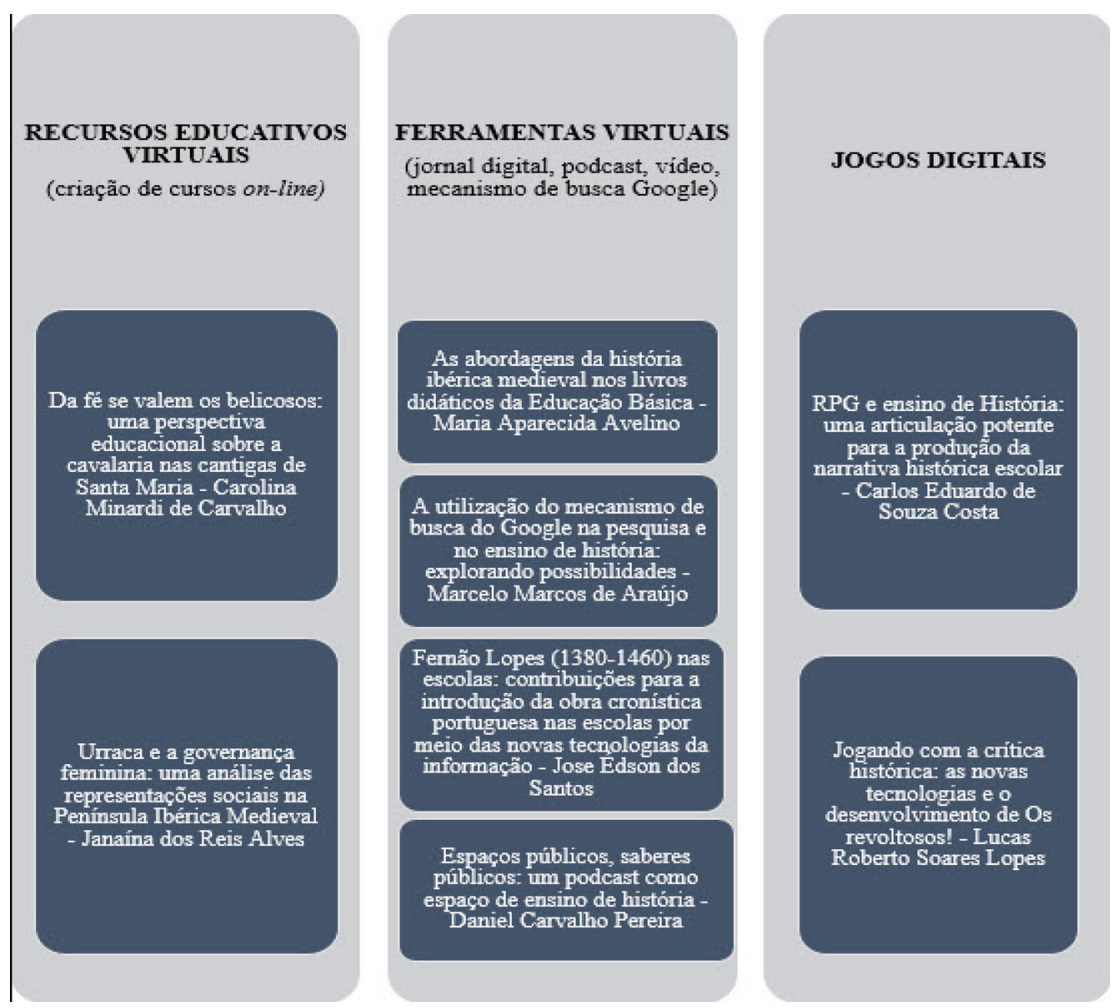

Fonte: quadro desenvolvido pelos autores (set. 2018). 
Os trabalhos analisados reconhecem as transformações que o ensino de História vem sofrendo, em decorrência, especialmente, do avanço de tecnologias digitais que criam novos espaços para a produção do conhecimento histórico. Nesse sentido, foi possível identificar que os holofotes focalizam o ciberespaço e as possibilidades educativas que as suas interativas e inúmeras ferramentas oferecem ao ensino de História, visto que $100 \%$ das obras analisadas abordam recursos virtuais no ensino dessa disciplina. Esse fato evidencia que, dentre as novas tecnologias, a internet, o ciberespaço e os seus recursos, relacionados ao ensino de História, são temas emergentes na academia nesses últimos anos.

Como ilustração, alguns estudos analisam o papel de ferramentas tecnológicas específicas, como o podcast (PEREIRA, 2016) e o uso do mecanismo de busca do Google para dinamizar o ensino de História, incentivando a pesquisa, a interação e a autoria; outros, o uso dos jogos (COSTA, 2017; LOPES, 2016) como potente recurso para trabalhar temporalidades, auxiliar na reelaboração da consciência histórica dos alunos e analisar fontes históricas, a partir da crítica histórica; outros, ainda, a produção de materiais didáticos, como cursos, vídeo educativo e jornal digital (CARVALHO, 2016; ALVES, 2017; AVELINO, 2017; SANTOS, 2016), devido à natureza profissional dos programas em que as pesquisas se desenvolveram, para ajudar a trabalhar a análise e a produção de narrativas históricas sobe a mulher ibérica na Idade Média, bem como os aspectos da História medieval, com vistas a promover a inovação de abordagens metodológicas dos conteúdos históricos.

Impende ressaltar, contudo, reforçando o que já foi mencionado ao longo do texto, que apenas a inserção de recursos tecnológicos na prática docente, sem uma mudança de concepção do que seja ensinar e aprender História, de metodologia e forma de avaliar não significa necessariamente inovação no ensino dessa disciplina (BITTENCOURT, 2008).

Um ponto que se destacou na análise dos dados foi que, apesar de todos as obras terem abordado o ciberespaço e as suas possibilidades educativas, nenhum deles tratou de metodologias atuais voltadas às tecnologias, como os métodos ativos, o que revela um silenciamento dos pesquisadores no que tange ao estudo de formas mais inovadoras e ousadas na inserção das tecnologias no ensino de História.

\subsection{Análise descritiva dos dados coletados nos artigos do Portal de Periódicos da Capes}

Segundo Hayashi (2004), as revistas ou periódicos, meios de divulgação e democratização do conhecimento científico e memória do que a ciência produz, surgiram no século XVII para substituir as cartas trocadas entre cientistas. A sua relevância para a sociedade é, portanto, inegável. Daí o interesse em investigar o que está sendo produzido nesse meio. 
A busca no portal dos periódicos da Capes, localizado no site oficial da fundação ${ }^{7}$, foi realizada no dia 12 de setembro de 2018. Inicialmente, foi utilizado como descritor o tema da pesquisa, "novas tecnologias e ensino de História", entre aspas, para precisar o resultado, mas o portal retornou um resultado zero. Por essa razão, o tema foi dividido em dois descritores: "novas tecnologias" e "ensino de história", ambos usados entre aspas; a busca retornou 24 resultados: 21 artigos e 3 livros. Como o objetivo era sistematizar a produção do tema em periódicos, em Tipo de recurso, refinou-se por artigo, restando 21 estudos.

Concluído esse processo de refinamento, o método usado para selecionar os artigos pertinentes ao tema da pesquisa foi, primeiramente, a leitura do título e, quando disponibilizado, do resumo na página central da pesquisa. Após essa leitura, 9 das 21 obras foram descartadas, por não fazerem referência aos descritores pesquisados. Para analisar a pertinência do restante dos artigos, foi feito o acesso à página do artigo completo, por meio do link "Detalhes" abaixo de cada resultado. Houve situações em que se tornou difícil acessar os artigos, em razão de o portal da Capes, instituição depositária, não disponibilizar o texto, mesmo contabilizando-o na sua base de dados de consulta. Nesses casos, o link nem sempre direcionava para o artigo, apenas para a página principal do periódico. Quando isso ocorria, utilizando o recurso de pesquisa da página do próprio periódico e o título do artigo, fazia-se a busca do artigo. Após acessar todos os artigos, a partir da leitura do título, resumo e palavras-chave, buscou-se selecionar somente os que abordavam a temática Novas tecnologias e ensino de História, o que resultou em 6 artigos a serem analisados.

Para uma melhor descrição e análise dos textos, foram feitos o download de todos os seis artigos e a leitura da introdução dessas produções. Para isso, organizou-se um quadro com os seguintes dados: título, autor, data de publicação e nome do periódico, conforme se verifica no Quadro 3.

É possível perceber, de acordo com o conteúdo do Quadro 3, que, pelo recorte temporal trazido pela pesquisa, de 2013 a 2018, o ano de 2015 foi o mais produtivo, com 2 dos 6 artigos publicados. Em termos de temática, os 5 periódicos nos quais os artigos foram publicados estão ligados às áreas da Educação (01), Educação, Tecnologia e Sociedade (01), História (02) e interdisciplinar (01), sendo que 4 deles foram avaliados pelo sistema Qualis. Há, também, uma vinculação de 5 dos 6 periódicos com instituições acadêmicas públicas, tanto federais como estaduais, espalhadas nas regiões Sul (01), Sudeste (01), Centro-Oeste (01), internacional (01) e, destacando-se, Nordeste (02), e uma, com instituição privada estrangeira.

\footnotetext{
7 Disponível em: http://www.periodicos.capes.gov.br. Acesso em: 12 set. 2018.
} 


\section{Quadro 3. Descrição dos artigos encontrados}

\begin{tabular}{|l|l|l|c|l|}
\hline & Título & Autor & $\begin{array}{c}\text { Ano de } \\
\text { publicação }\end{array}$ & Periódico \\
\hline 01 & $\begin{array}{l}\text { Os desafios da educação contemporânea: o ensino } \\
\text { de História e o emprego das novas tecnologias }\end{array}$ & $\begin{array}{l}\text { Camila Gonçalves Silva e } \\
\text { Vítor Fonseca Figueiredo }\end{array}$ & 2013 & Revista Opsis (UFG) \\
\hline 02 & $\begin{array}{l}\text { Professores de história: o uso do computador na } \\
\text { construção do conhecimento histórico escolar }\end{array}$ & $\begin{array}{l}\text { Cyntia Simioni França e } \\
\text { Cristiano Biazzo Simon }\end{array}$ & 2014 & $\begin{array}{l}\text { Tempo e Argumento } \\
\text { (UDESC) }\end{array}$ \\
\hline 03 & $\begin{array}{l}\text { Educação e Tecnologias: inter-relações entre teoria } \\
\text { e práticas pedagógicas no processo de ensino e } \\
\text { aprendizagem no ensino fundamental }\end{array}$ & $\begin{array}{l}\text { Raylson dos Santos Cutrim e } \\
\text { Francisco Renato Lima }\end{array}$ & 2015 & $\begin{array}{l}\text { Brazilian Journal of Education, } \\
\text { Technology and Society } \\
\text { (UMinho - PT) }\end{array}$ \\
\hline 04 & $\begin{array}{l}\text { Iniciação à docência e ensino de História - } \\
\text { desafios na contemporaneidade }\end{array}$ & $\begin{array}{l}\text { Fábio André Hahn e } \\
\text { Adaiane Giovanni }\end{array}$ & $\begin{array}{l}\text { Revista Ibero-Americana de } \\
\text { Estudos em Educação (UNESP) }\end{array}$ \\
\hline 05 & $\begin{array}{l}\text { A gamificação no ensino de História: o jogo } \\
\text { "Legend of Zelda" na abordagem sobre } \\
\text { medievalismo }\end{array}$ & $\begin{array}{l}\text { Dayse Marinho Martins, } \\
\text { João Batista Bottentuit Junior, } \\
\text { A. A. Marques e N. M. Silva }\end{array}$ & 2016 & Holos (IFRN) \\
\hline 06 & $\begin{array}{l}\text { O ensino de História na educação a distância } \\
\text { (EAD): novos caminhos para a aprendizagem } \\
\text { online }\end{array}$ & $\begin{array}{l}\text { Lívia Badaró Fabricio, } \\
\text { Suélly Lima dos Santos, } \\
\text { Janete Araci do Espírito Santo } \\
\text { e Liliane Ribeiro Moreira }\end{array}$ & 2018 & Holos (IFRN) \\
\hline
\end{tabular}

Fonte: Quadro desenvolvido pelos autores (set. 2018).

O baixo número de artigos encontrados surpreendeu, já que, na busca, não se fez uso de nenhum critério, excetuando-se o do tipo de produção. Isso demonstra uma preocupação ainda limitada com relação ao estudo do tema no âmbito acadêmico. No que diz respeito à autoria dos artigos, todos foram escritos por estudiosos brasileiros, totalizando 16 autores e coautores. Quanto ao vínculo institucional desses pesquisadores, verificou-se a sua associação com várias instituições de nível superior (UFJF/MG, UNESPAR/PR UNOPAR/PR, UNICAMP, UEL/PR, FLATED/ CE, UFPI, UENF/RJ, IFF/RJ, UFMA), além da Secretaria de Educação do Rio de Janeiro.

No que tange à base teórica dos estudos narrados, somente um trabalho apontou, no resumo, a teoria em que se fundamentou para desenvolver a pesquisa, o que tornou necessário ler a introdução dos demais trabalhos. Esse silenciamento evidencia a insuficiência de elementos informativos na estrutura de grande parte dos resumos em trabalhos científicos, além da falta de preocupação do pesquisador com o rigor metodológico, já que 50\% dos artigos não cita, de modo claro, sua base teórica, nem mesmo na introdução dos textos.

Com relação ao tipo de pesquisa, dos seis estudos relatados, duas eram pesquisas bibliográficas e quatro, de campo. Essa preponderância da pesquisa empírica pode estar relacionada ao interesse na busca por alternativas 
metodológicas para o ensino de História em um contexto altamente tecnologizado e conectado, fato reforçado pela escolha dos objetos de estudo das pesquisas. Do total de artigos analisados, quatro abordam as tecnologias em geral, enfatizando a perspectiva do (des)uso e/ou metodologia utilizada pelo professor ao inserir os recursos tecnológicos na prática pedagógica, enquanto dois investigam tecnologias específicas (computador e jogo digital).

No que se refere às temáticas investigadas, todos os artigos analisados $(100 \%)$ discutem o uso das tecnologias como recurso e metodologia para fomentar tanto o ensino como a pesquisa histórica. Do debate sobre o jogo eletrônico como perspectiva metodológica, com base nas contribuições da Nova História ao papel do computador na construção do conhecimento histórico escolar, nota-se uma preocupação com os novos desafios que surgem no ensino de História a partir da presença das tecnologias na escola e na sociedade contemporânea. Nessa discussão sobre a inserção das tecnologias no ensino de História, enfatiza-se, também, a importância da formação continuada dos professores como elemento potencializador de um uso crítico e reflexivo.

Constata-se, mais uma vez, que as pesquisas nesse campo, apesar de ainda estarem principiando, como demonstrou a escolha temática de $67 \%$ dos artigos analisados, confluem ao abordar a preocupação em estudar as novas tecnologias e descobrir formas de inseri-las no processo educativo, de modo a ressignificar as práticas pedagógicas transmissivistas, memorísticas e verbalistas que têm prevalecido no ensino de História. Todos os trabalhos evidenciam a preocupação com um ensino de História alijado do contexto social, incapaz, assim, de despertar a consciência histórica do aluno da era digital. As tecnologias são parte do mundo do aluno, por isso, "quanto mais o aluno sentir a História como algo próximo dele, mais terá vontade de interagir com ela" (KARNAL, 2005, p. 18). Não se pode esquecer, entretanto, que a mera inserção das tecnologias na sala de aula não significa necessariamente alteração na forma de ensinar. É preciso reformular as concepções e as práticas educativas.

\section{Considerações finais}

A partir da leitura dos dados analisados no presente trabalho, foi possível fazer algumas inferências que permitem, de modo resumido, indicar alguns pontos interessantes:

a) apesar de as novas tecnologias no ensino de História ser uma temática emergente, tanto no âmbito da pósgraduação como das publicações científicas, a produção e a divulgação nesse campo ainda se mostra incipiente;

b) há uma tendência investigativa, dentro do tema novas tecnologias e o ensino de História, direcionada ao estudo da internet e suas ferramentas;

c) nem sempre é possível identificar a temática do estudo pelo título, já que, em alguns trabalhos, não há relação entre esses dois elementos (HAHN; GIOVANNI, 2015; AVELINO, 2017; ALVES, 2017; CARVALHO, 2016); 
d) o ciberespaço e as suas ferramentas têm sido a temática mais estudada em nível de mestrado, enquanto nas publicações em periódicos, as novas tecnologias, em geral, se destacaram. A despeito de tal distinção, há a confluência do interesse, nesse âmbito, na incorporação, uso e metodologia apropriada para o trabalho com esses recursos tecnológicos;

e) detectou-se uma intensa preocupação em buscar formas de inovar, por meio da inserção das tecnologias na prática pedagógica, o ensino de História;

f) do ponto de vista metodológico, os resumos apresentaram várias lacunas referentes a informações relevantes para o desenvolvimento do mapeamento, especialmente quanto ao tipo de pesquisa, técnicas de coleta de dados e teorias que fundamentam os trabalhos. Ainda que essas lacunas possam ser superadas pela leitura da introdução, o silenciamento atrasa o processo descritivo-analítico dos dados, além de demonstrar que há pouca preocupação com o rigor metodológico por parte dos avaliadores dos periódicos e dos pesquisadores e universidades onde desenvolvem suas pesquisas.

Por fim, um aspecto promissor pontuado pelos resultados refere-se à preocupação em investigar as novas tecnologias na perspectiva de discutir a sua utilização para revitalizar o ensino de História. Em ambos os tipos de produção, dissertações e artigos, os pesquisadores se debruçam, assim, na possibilidade de estudar as teorias a partir do caso concreto, buscando, com isso, relacionar academia e escola, de modo a renovar a prática profissional, especialmente nas dissertações vinculadas a programas de mestrado profissional, exercitando a reflexão na ação.

\section{Referências}

ALVES, Janaína dos Reis. Urraca e a governança feminina: uma análise das representações sociais na Península Ibérica medieval. 2017. Dissertação (Mestrado Profissional em Ensino de História) - Universidade Federal de Alfenas, Alfenas, 2017. Disponível em: https://sucupira.capes.gov.br/sucupira/public/consultas/ coleta/trabalhoConclusao/viewTrabalhoConclusao.jsf?popup=true\&id_ trabalho=5634779. Acesso em: 05 set. 2018. https://doi.org/10.1590/0103-1104201611123

ANDRÉ, Marli E. D. A. A produção acadêmica sobre formação de professores: um estudo comparativo das dissertações e teses defendidas nos anos 1990 e 2000. Formação Docente, Belo Horizonte, v. 01, n. 01, p. 41-56, ago./dez. 2009. Disponível em: http://formacaodocente.autenticaeditora.com.br/artigo/exibir/1/7/3. Acesso em: 5 jun. 2018. https://doi.org/10.1590/198321172008100103

ARAÚJO, Marcelo Marcos de. A utilização do mecanismo de busca do Google na pesquisa e no ensino de História: explorando possibilidades. 2016. Dissertação (Mestrado Profissional em Ensino de História) - Universidade Federal do Tocantins, 2016. Disponível em: https://goo.gl/9PxkF3. Acesso em: 05 set. 2018. https://doi.org/10.18605/2175-7275/cereus.v9nep113-124 
ARRUDA, Eucídio Pimenta. Cultura e ensino de história na perspectiva das redes sociais e do ciberespaço. In: SILVA, Cristiani Bereta da; ZAMBONI, Ernesta (org.). Ensino de história, memória e culturas. Curitiba, PR: CRV, 2013. p. 35-53. https://doi. org/10.24824/978858042581.9

ARRUDA, Eucídio Pimenta. Aprendizagem e jogos digitais. Campinas, SP: Alínea, 2011.

ARRUDA, Eucídio Pimenta. Aprender História com jogos digitais em rede: possibilidades e desafios para os professores. In: MAGALHÃES, Marcelo et al. (org.). Ensino de História: usos do passado, memória e mídia. Rio de janeiro: FGV Editora, 2014. p. 239-253. https://doi.org/10.5433/2238-3018.2019v25n1p561

AVElinO, Maria Aparecida. As abordagens da História Ibérica Medieval nos livros didáticos da Educação Básica. 2017. Dissertação (Mestrado Profissional em Ensino de História) - Universidade Federal de Alfenas, Alfenas, 2017. Disponível em: https://sucupira.capes.gov.br/ sucupira/public/consultas/coleta/trabalhoConclusao/ viewTrabalhoConclusao.jsf?popup=true\&id trabalho=5012796. Acesso em: 05 set. 2018. https://doi.org/10.5380/his.v67i1.58066

BITTENCOURT, Circe M. F. Ensino de História: fundamentos e métodos. 2. ed. São Paulo: Cortez, 2008.

CARVALHO, Carolina Minardi de. Da fé se valem os belicosos: uma perspectiva educacional sobre a cavalaria nas cantigas de Santa Maria. 2016. Dissertação (Mestrado Profissional em Ensino de História) - Universidade Federal de Alfenas/MG, Alfenas, 2016. Disponível em: https://sucupira.capes.gov.br/sucupira/public/consultas/ coleta/trabalhoConclusao/viewTrabalhoConclusao. jsf?popup=true\&id_trabalho=3922987. Acesso em: 05 set. 2018. https://doi.org/10.1590/0103-1104201611123

COSTA, Carlos Eduardo de Souza. RPG e ensino de História: uma articulação potente para a produção da narrativa histórica escolar. 2017. Dissertação (Mestrado Profissional em Ensino de História) - Universidade Federal do Rio de janeiro. 2017. Disponível em: https://goo.gl/5Qmi19. Acesso em: 05 set. 2018. https://doi.org/10.17013/risti.23.90-102

CUTRIM, Raylson dos Santos; LIMA, Francisco Renato. Educação e tecnologias: inter-relações entre teoria e práticas pedagógicas no processo de ensino e aprendizagem no ensino fundamental. Brazilian Journal of Education, Technology and Society (Cad. Ed. Tec. Soc.), Inhumas, v. 8, n. 2, p. 148-165, 2015. Disponível em: http://www.brajets.com/index.php/brajets/article/ view/244. Acesso em: 20 set. 2018. https://doi.org/10.14571/cets.v8i2.244

FABRÍCIO, Lívia Badaró et al. O ensino de História na educação a distância (EAD): novos caminhos para a aprendizagem online. Revista Holos, ano 34, v. 2, p. 307-317, 2018. Disponível em: http://www2.ifrn.edu.br/ojs/index.php/HOLOS/article/ view/3255/pdf. Acesso em: 20 set. 2018. https://doi.org/10.15628/holos.2018.3255

FERREIRA, Norma Sandra de A. As pesquisas denominadas "estado da arte". Revista Educação \& Sociedade, Campinas, ano XXIII, n. 79, p. 257-272, ago. 2002. https://doi.org/10.1590/s0101-73302002000300013 
FONSECA, Selva Guimarães. Didática e prática de ensino de História: experiências, reflexões e aprendizados. 13. ed. rev. e ampl. Campinas/SP: Papirus, 2012.

FRANÇA, Cyntia Simioni; SIMON, Cristiano Biazzo. Professores de história: o uso do computador na construção do conhecimento histórico escolar. Revista Tempo e Argumento, Florianópolis, v. 6, n. 12, p. 186-211, maio/ago. 2014. Disponível em: http://revistas.udesc.br/index.php/tempo/article/view/2175180306122014186/3647. Acesso em: 20 set. 2018. https://doi.org/ $10.5965 / 2175180306122014186$

HAHN, Fábio André; GIOVANNI, Adaiane. Iniciação à docência e ensino de História - desafios na contemporaneidade. Revista Ibero-Americana de Estudos em Educação, v. 10, n. 2, p. 430-444, abr./jun. 2015. Disponível em: https://periodicos.fclar.unesp.br/ iberoamericana/article/view/7529/5397. Acesso em: 20 set. 2018. https://doi.org/10.21723/riaee.v14iesp.2.12614

HAYASHI, Carlos R. M. Presença da educação brasileira na base de dados Francis: uma abordagem bibliométrica. 2004. Disponível em: https://repositorio. ufscar.br/bitstream/handle/ufscar/2487/2568.pdf?sequence=1. Acesso em: 21 set. 2018.

KARNAL, Leandro (org.). História na sala de aula. São Paulo: Contexto, 2005.

LÉVY, Pierre. Cibercultura. São Paulo: Editora 34, 1999.

LOPES, Lucas R. S. Jogando com a crítica histórica: as novas tecnologias e o desenvolvimento de "Os revoltosos". Dissertação (Mestrado Profissional em Ensino de História) - Universidade do Estado de Santa Catarina, 2016. Disponível em: https://goo.gl/ GTHrnS. Acesso em: 05 set. 2018. https://doi.org/10.17533/udea.efyd.v34n2a02

MARTINS, Dayse Marinho et al. A gamificação no ensino de História: o jogo "Legend of Zelda" na abordagem sobre medievalismo. Revista Holos, ano 32, v. 7, p. 299-321, 2016. Disponível em: http:/www2.ifrn.edu.br/ojs/index.php/HOLOS/article /view/1978. Acesso em: 20 set. 2018. https://doi.org/10.15628/holos.2016.1978

MINAYO, Maria Cecília de S.; SANCHES, Odécio. Quantitativo-qualitativo: oposição ou complementaridade? Caderno Saúde Pública, Rio de Janeiro, v. 9, n. 3, p.239-262, jul./set. 1993. Disponível em: https://goo.gl/1BskAn. Acesso em: 2 jun. 2018. https://doi.org/10.1590/s0102-311x1993000300002

PEREIRA, Daniel Carvalho. Espaços públicos, saberes públicos: um podcast como espaço de em sino de história. Dissertação (Mestrado Profissional em Ensino de História) - Universidade do Estado do Rio de Janeiro, Rio de Janeiro, 2016. Disponível em: https://goo.gl/awZ5pQ. Acesso em: 05 set. 2018. https://doi.org/10.17771/pucrio.acad.35563

PRENSKY, Marc. Nativos Digitais, Imigrantes Digitais. NCB University Press, v. 9, n. 5, out. 2001. Disponível em: http://www. colegiongeracao.com.br/novageracao/2_intencoes/ nativos.pdf. Acesso em: 2 set. 2018. 
ROMANOWSKI, Joana P.; ENS, Romilda T. As pesquisas denominadas “estado da "arte em educação. Diálogo Educacional,

Curitiba, v. 6, n. 19, p. 37-50, set./dez. 2006. Disponível em: http://www2.pucpr.br/reol/pb/index.php/dialogo?dd1=237\&dd 99=view. Acesso em: 05 jun. 2018. https://doi.org/10.7213//dialogo.educ.13.040.ds03

SANTOS, José Edson dos. Fernão Lopes (1380-1460) nas escolas: contribuições para a introdução da obra cronística portuguesa nas escolas por meio das novas tecnologias de informação. Dissertação (Mestrado Profissional em Ensino de História) -

Universidade Federal de Alfenas, Alfenas, 2016. Disponível em: https://bdtd.unifal-mg.edu.br:8443/bitstream/tede/905/5/

Disertação\%20de\%20 Jose\%20Edson\%20dos\%20Santos.pdf. Acesso em: 5 set. 2018. https://doi.org/10.14198/geoalicante 2015.22

SEFFNER, Fernando. Aprender e ensinar história: como jogar com isso? In: GIACOMONI, Marcello Paniz; PEREIRA, Nilton Mullet (org.). Jogos e ensino de História, Porto Alegre: Evangraf, 2013. p. 25-46.

SILVA, Camila Gonçalves; FIGUEIREDO, Vítor Fonseca. Os desafios da educação contemporânea: o ensino de História e o emprego das novas tecnologias. Revista Opsis, Catalão, v. 13, n. 1, p. 99-119, jan./jun. 2013. Disponível em: https:// revistas.ufg.br/ Opsis/article/view/20483/15177\#.W6ZMI-XPyM9. Acesso em: 20 set. 2018. https://doi.org/10.5216/o.v13i1.20483

Recebido em: 3/10/2018.

Aprovado em: $1 / 3 / 2019$.

Publicado em: 31/12/2019.

\section{Endereço para correspondência:}

Paulo Augusto Tamanini

Rua Francisco Ignácio do Nascimento, 470

88107-500, São José, SC, Brasil

\section{Autores:}

Paulo Augusto Tamanini

Pós-Doutorado em História pelo Programa Nacional de Pós-Doutorado CAPES/UFPR (2015-2017). Doutor em História pela Universidade Federal de Santa Catarina (2013). Mestre em História pela Universidade do Estado de Santa Catarina (2010). Especialização em Teologia Bizantina, pela

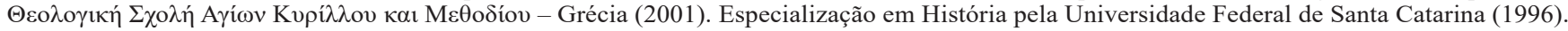
Possui Licenciatura em Filosofia pela UNIFEBE (1991) e Licenciatura em História pelo Centro Universitário Claretiano (2018).

Professor Orientador no Programa de Pós-Graduação em Ensino (UFERSA/UERN/IFRN). Coordenador do Grupo de Pesquisa: Imagens e Ensino.

percepções, métodos e fontes (CNPq). Membro do Athens Institute for Education and Research (ATINER) e do Athens Center for Classical \& Byzantine Studies (Atenas, Grécia). Integrante do Comitê Científico das Revistas: Fogón - Revista de Estudios de las Tradiciones (Chile) e Revista Contraponto do PPGHB (UFPI).

Orcid: http://orcid.org/0000-0001-6963-2952

E-mail: paulo@tamanini.com.br 


\section{Maria do Socorro Souza}

Mestra em ensino pelo Programa de Pós-Graduação em Ensino (POSENSINO) da Universidade Federal Rural do Semi-Árido (UFERSA). Professora do

Núcleo Tecnológico Educacional Jerônimo Rosado (NTE) e do Núcleo de Tecnologia Educacional Municipal (NTM) de Mossoró-RN, ministrando cursos

de formação para a inserção das Tecnologias na Educação aos professores da rede pública da Educação Básica do RN. Tem experiência na área de Educação, com ênfase em Informática Educativa, em línguas (Inglês e Português) e em EaD.

Orcid: http://orcid.org/0000-0003-2373-6101

E-mail: socsouza@hotmail.com

Endereço: Escola Estadual Jerônimo Rosado - Núcleo de Tecnologia Educacional

Rua Ferreira Itajubá, s/n - Santo Antonio

59611-030, Mossoró, RN, Brasil 